\title{
Glaze Epochs: Understanding Lifelong Material Relationships within Ceramics Studios
}

\author{
Hedieh Moradi \\ hedieh.moradi@mavs.uta.edu \\ The University of Texas at Arlington \\ Arlington, Texas, USA \\ Quyen-Anh Valentina Nguyen \\ quyenanh.nguyen@mavs.uta.edu \\ The University of Texas at Arlington \\ Arlington, Texas, USA
}

\author{
Long N. Nguyen \\ long.nguyen6@mavs.uta.edu \\ The University of Texas at Arlington \\ Arlington, Texas, USA \\ Cesar Torres \\ cearto@uta.edu \\ The University of Texas at Arlington \\ Arlington, Texas, USA
}
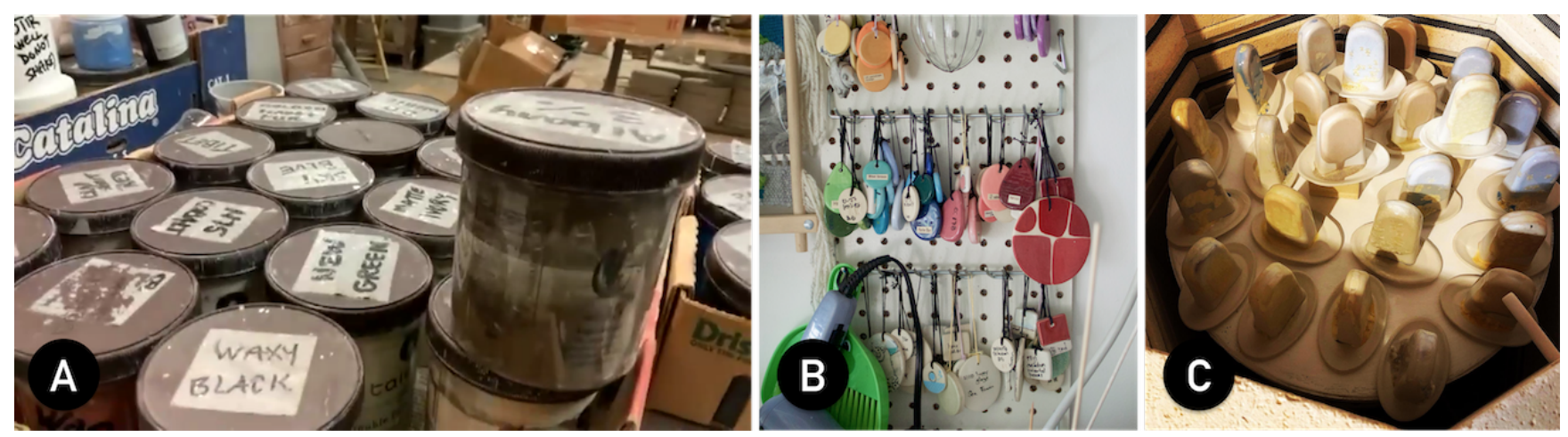

Figure 1: A) A ceramics instructor labels personal time-tested glazes for her studio, B) a production ceramicist hangs a collection of glaze keys that allow her reference and share her glaze and clay body combinations with others in her communal studio; C) a ceramics engineer systematically fires variations of a glaze recipe for documentation and analysis.

\begin{abstract}
The "material turn" in HCI has placed a renewed focus on informing design from the relationships found in material-based interactions. While several ethnographic works provide insight into how practitioners converse with materials, it is less understood how these conversations transform into a skilled practitioner's relationship with a material. We examine the material practice of glazing that gives ceramics its decorative and functional characteristics and involves fusing mixtures of silica, alumina, and flux onto a clay body through kiln firing. This practice evolves over decades developing from multiple trajectories including theoretical foundations, systematic experimentation, and happy accidents. This work describes virtual site visits with six expert ceramicists and documents how material knowledge is externalized in practice, teaching, and the studio environment. We synthesize our findings into a framework
\end{abstract}

This work is licensed under a Creative Commons Attribution International 4.0 License.

TEI '22, February 13-16, 2022, Daejeon, Republic of Korea

(c) 2022 Copyright held by the owner/author(s).

ACM ISBN 978-1-4503-9147-4/22/02.

https://doi.org/10.1145/3490149.3501310 to inform the design of material interactions that moves beyond discrete and momentary material encounters towards lifelong material epochs.

\section{CCS CONCEPTS}

- Applied computing Fine arts; • Human-centered computing Empirical studies in interaction design.

\section{KEYWORDS}

Materiality, Creativity Support Tools, Design

\section{ACM Reference Format:}

Hedieh Moradi, Long N. Nguyen, Quyen-Anh Valentina Nguyen, and Cesar Torres. 2022. Glaze Epochs: Understanding Lifelong Material Relationships within Ceramics Studios. In Sixteenth International Conference on Tangible, Embedded, and Embodied Interaction (TEI '22), February 13-16, 2022, Daejeon, Republic of Korea. ACM, New York, NY, USA, 13 pages. https://doi.org/10. $1145 / 3490149.3501310$

\section{INTRODUCTION}

The "material turn" describes a transformation in how interaction designers think about relations between physical and digital materials $[31,46]$. This turn has placed a renewed focus on developing a vocabulary around how physical and computational materials are used in interaction design. Many of these approaches focus on making salient the rich interactions of materials with each other 
(e.g., making as correspondence [17], crafting proxies [40]), the responsiveness of materials under investigation (e.g., performativity [2]), or as part of the relationships with materials that arise from engaging in a craft practice (e.g., making preciousness [42], wayfaring [17]). For interaction designers, drawing from material relationships is especially valuable for stimulating novel creative connections [44] and allowing practitioners to work with new media, smart materials, and digital materials [45].

Over the course of a lifetime, a practitioner will interact thousands of times with a material, finding new creative trajectories that keep them sustained within their practice. This lifelong relationship, which we term the material epoch, includes both extrinsic and intrinsic motivators that cause a practitioner to engage with a material, the creative choices taken or followed, and how these creative outcomes inform future material encounters. Within communities of practice, these relationships present themselves in practitioners with a lifetime of experience; understanding how to nurture these relationships can be used to design creative technologies that sustain and immerse newcomers in creative activity. Although the tools and methods proposed by interaction designers focus on supporting material interactions in the moment, opportunities exist for understanding how creative technologies might help to develop and evolve a practitioner's relationship with a material.

This work acts as a step towards identifying the material epochs of six expert ceramicists with 163 years of combined experience in ceramic practice. Through a virtual contextual inquiry [3], we observe and probe how an expert's material relationship has been developed and refined through the ways they work, set up their environment, capture, document, and store their findings, and transfer material knowledge with each other. We place our focus on the practice of glazing that gives ceramics its decorative and functional characteristics. Glazing is rarely a deterministic activity; a glaze can change dramatically from environmental phenomena (e.g., oxygen level inside a kiln), its application technique (e.g., dipped), its composition (e.g., oxide balance), or its placement on clay body geometries (e.g., textures). Nevertheless, the diversity and complexity of glazing interactions exemplify a deep material relationship that we aim to better understand.

Our site visits reveal a stark difference between the theory and practice of how potters manipulate and use glazes and documents the different ways material knowledge is generated and externalized in their studio environments. We synthesize our findings into a framework that describes how creative activity with material interactions is elicited, the formal dimensions that ceramicists navigate, and the way that intermediary and finished artifacts alter a practitioner's relationship with the material. Lastly, we provide recommendations for how creativity support tools can provoke creative activity, how material knowledge can be developed, and how choosing not to externalize material knowledge has value in supporting curiosity and exploration.

\section{RELATED WORK}

Material-based inquiry is an active research area explored by makers and designers with a special focus on the digital fabrication and smart material communities. We describe studies around material practices, externalizing material knowledge, and ceramics.

\subsection{Investigating Material Practices}

Within HCI, studies of making and craft have been used to motivate the design of domain-specific tools. Maudet et al. [24] investigated how professional graphic designers create and structure layouts for digital and print media; their observations revealed that the "grid" only represented a small subset of the strategies used by designers and presented a framework capturing these strategies to motivate the design of layout tools. Our work leverages a similar methodology to construct a framework for supporting creativity support tools in material practices. Other ethnographic works have focused on understanding technological frictions with materials. Rosner et al. [33] presented findings from ethnographic interviews with six ceramicists to understand their material relationships with clay and obstacles in integrating clay with technology; this work further explores these relationships in artist-researcher collaborations by embedding electronics and audio signatures into clay forms. Zheng et al. [49] engaged in a co-design research approach between an interaction designer and ceramic artist to navigate tensions between craft and design processes in creating an interactive lamp. We build on these endeavors by examining how technology might support time-tested practices such as glazing that have mature material relationships.

Several methods have been proposed for identifying and capturing tacit knowledge in complex craft domains. Wood et al. [47] described the use of an expert learner to serve as an intermediary between the novice and expert, capturing tacit knowledge before it can be internalized. Tacit knowledge has also been examined through video analysis of master ceramicists in China and Taiwan [13], using contextual inquiry to document failure-mitigation strategies in ceramics [39], through blindfolding artist-researchers to enhance tactile sensitivity and awareness [14], through reflecting on electromyography (EMG) readings taken while throwing pots [23], and in observing skill transfer of novices learning to throw pots using book, web, and video tutorials [10].

Rosner [32] leveraged participant observation during a threemonth bookbinding apprenticeship and proposed a broader definition of collaborative work that includes interactions among materials, people, and workspaces. The emphasis of human and nonhuman actors in creative process has been further explored in conceptualizing Internet of Things technologies [22], extending 3D printing practices to highlight material indeterminacy and resistance, and foregrounding a material's life history to promote sustainable design [8]. We build on this body of work by examining the material relationships of master ceramicists across diverse ceramic practices; we leverage these insights to inform how technology may better externalize tacit information in material practices.

\subsection{Externalizing Tacit Knowledge}

Externalizing tacit information has had traction within the tangible computing community. Khairuddin et al. [19] developed a tangible kit for communicating the intricacies and infrastructures of blockchain technologies through material affordances. Others within the design community have begun developing toolkits that aim to improve or transfer material knowledge. Murer [26] proposed a framework for designing un-crafting activities that build 


\begin{tabular}{|c|c|c|c|c|c|c|}
\hline Ceramic Practice & \multicolumn{4}{|c|}{ Informants (Gender I Age I Experience) } & \multirow{2}{*}{$\begin{array}{l}\text { Background } \\
\text { Art Therapist - Expert Amateur } \\
\text { Uses commercial glazes; } \\
\text { formal training in ceramics. }\end{array}$} & \multirow{2}{*}{$\begin{array}{l}\text { Site } \\
\text { Personal at-home studio. } \\
\text { Occasional sales through } \\
\text { Facebook Marketplace. }\end{array}$} \\
\hline $\begin{array}{c}\text { Ty } \\
\text { Hobbyist } \\
\text { Ceramicist }\end{array}$ & Seneca & $\mathbf{F}$ & 34 & 12 & & \\
\hline \multirow{3}{*}{$\underbrace{\text { Studio Potter }}_{\text {Production/ }}$} & Ruth & $\mathbf{F}$ & 70 & 30 & $\begin{array}{l}\text { Production potter; teaches } \\
\text { studio classes. }\end{array}$ & $\begin{array}{l}\text { Ceramics storefront and } \\
\text { personal studio in backroom. }\end{array}$ \\
\hline & Edison & M & 72 & 51 & $\begin{array}{l}\text { Studio potter. Teaches studio } \\
\text { classes only to advance students. } \\
\text { Donates his work to galleries to } \\
\text { support the community and } \\
\text { increase engagement. }\end{array}$ & $\begin{array}{l}\text { Personal studio; uses } \\
\text { sensor-retrofitted kiln. }\end{array}$ \\
\hline & Leila & $\mathbf{F}$ & 49 & 30 & Functional production potter. & $\begin{array}{l}\text { Studio within a ceramics collective } \\
\text { with } 20 \text { other ceramic artists. }\end{array}$ \\
\hline & Paul & M & 36 & 20 & $\begin{array}{l}\text { Instructor of college-level } \\
\text { ceramics course. }\end{array}$ & $\begin{array}{l}\text { College instruction ceramics } \\
\text { classroom. }\end{array}$ \\
\hline $\begin{array}{l}\text { Ceramic } \\
\text { Engineer }\end{array}$ & Jackson & M & 43 & 20 & $\begin{array}{l}\text { Systematic documentation with } \\
\text { professional photo rig. Runs } \\
\text { online glaze workshop. }\end{array}$ & $\begin{array}{l}\text { Glazing lab with chemical } \\
\text { benches. }\end{array}$ \\
\hline
\end{tabular}

Table 1: Informant Backgrounds, Sites, and Practices. Pseudonyms are used to maintain informant confidentiality.

knowledge through decomposition of materials that place a material under inspection (inquiry), explore variations of that materials (exploration), show the material in context (exposition), and attempting new material compositions from previous activities (inspiration). Wood et al. [48] proposed bridging the expert-novice gap through a destructive analysis of practice to extract and capture principles before they are internalized through practice.

Others have explored how external documentation connects with learning processes. Chen et al. [5] used a journey map design probe to have students chart different documentation practices throughout course projects to better understand values placed on documentation. Torrey et al. [41] examined documentation practices of computer and electronic hobbyists, revealing a dual purpose in both documenting processes and broadcasting a maker's expertise. Our work builds on further identifying how knowledge is internalized or documented over time, especially to refine and expand on personal practice.

\subsection{Technology in Ceramics Practices}

Within ceramics, research has focused on connecting emerging technology to more traditional craft practices. Several studies have examined collaboration with artisans to understand how computer numerical controlled (CNC) tools would be appropriated by craft practices in art furniture production [4] and ceramic [34] practices. Other work has explored digital fabrication processes to enhance or extend ceramic practices. Zoran et al. [50] reconstructed a broken ceramics object with 3D-printed elements exploring how uniqueness could be reimbued to an artifact through destruction and restoration. Dick et al. [9] described a technique for controlling the cracking of glaze, or crazing, by identifying the relationship between surface treatment and glaze thickness; we include similar ceramic research strategies when interviewing ceramic engineers in our contextual inquiry.
Ceramics practices often keep track of glazing recipes through physical test tiles. Within ceramics research, the Ceramics Color Database aims to make available the 300,000 test pieces of AIST Japan, but the curation and entry of these tiles into a virtual database has stifled efforts, with only $4 \mathrm{~K}$ openly available [37]. In 2020, community-driven efforts led to the recent creation and adoption of Glazy.org [1], an open platform for sharing and analyzing over $6.8 \mathrm{~K}$ ceramics recipes (at the time of writing).

\section{METHODOLOGY}

To better understand a complex task like glazing, we leveraged the expertise of ceramicists with decades of glazing experience. Because material relationships rely heavily on tacit knowledge, it is crucial to study user-material interactions in the moment or space that they are used in. We elected to conduct a rapid design ethnography using contextual inquiry [3,25]. Using contextual inquiry enabled us to achieve an interactive [25] and in-depth observation [35] from users in their natural studio-workshop setup.

\subsection{Participant Recruitment and Selection}

We conducted site visits with 6 ceramic artists ( 3 male, 3 female), ages 34 to 72, with an average of $27 \pm 5$ years of experience. Informants were recruited initially through local ceramic listservs followed by snowball recruiting. Participants were pre-screened using a questionnaire to assess for expertise and to confirm that participants had access to a studio. A summary of each informant's background and experience is depicted in Table 1; informants came from diverse fields of ceramics (Table 1) including an art therapist and hobbyist potter, functional studio and production ceramicists, studio and college instructors, storefront owners and communal potters, and ceramic engineers. All informants had formal degrees in ceramics. Although we were unable to recruit informants from a purely artistic practice, all informants had produced artistic work (e.g., for gallery exhibition) at some point in their careers. Because 


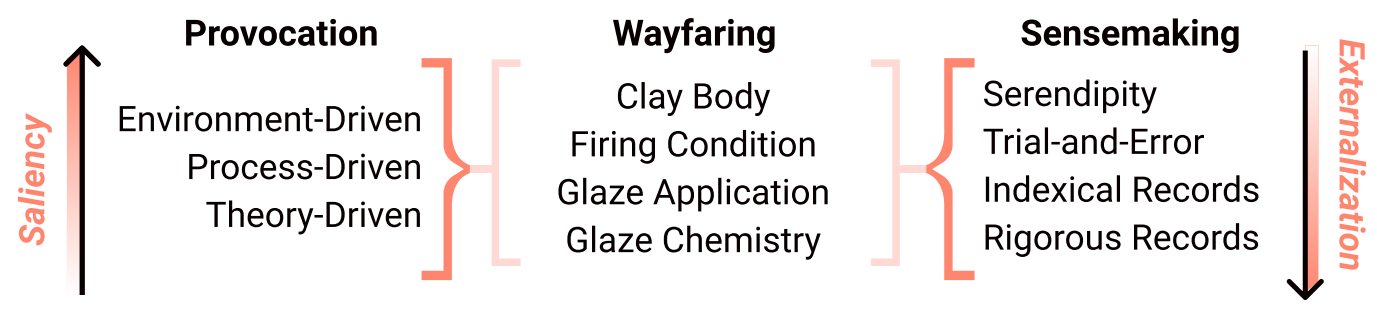

Figure 2: Material Knowledge Creation and Refinement We organize these factors based on a practitioner's access to tools, materials, or knowledge needed to engage with each factor.

of the virtual nature of the contextual inquiry, our final informant pool was all US-based and covered a large part of the United States cultural geography (e.g., East, West, South, Midwest). Some informants had experience with artist-in-residence programs abroad in Asia and Europe.

\subsection{Procedure}

Five informants participated in an hour-long virtual site visit using Zoom (during the COVID-19 pandemic), and one informant was interviewed in person at their collective-based studio (before the COVID-19 pandemic). Informants were compensated at a rate of $\$ 25 / \mathrm{hr}$. To maintain the benefits of a site visit, participants were asked to use their phones and their rear-facing camera during the virtual visit. Although the research team was familiar with many glaze practices, we were careful to frame ourselves as ceramics beginners to maintain a master-apprentice relationship with informants. To better empathize and understand the glazing practices described and gauge areas to probe, the paper authors engaged in replicating glazing strategies in a clay studio. Notes were collected for each visit, and screen recordings were audio transcribed; screenshots were extracted from video to form photo logs. Informants were asked to show and walkthrough artifacts, processes, or workspaces that were referenced when answering our questions. We probed specifically on their glazing process, documentation, use of technology, storage system, and sharing culture within their community of practice.

Our final dataset included 5.5 hours of video/audio data from 6 informants, 165 extracted and annotated screenshots, and 37 pages of audio transcripts and notes. We followed up with informants in situations where we needed a clearer image, needed to disambiguate one of the transcript items, or to ask for clarification on a concept or process discussed. Two paper authors with background ceramics knowledge conducted a thematic analysis [6], each independently iteratively applying and developing inductive codes to the dataset of transcripts and annotated screenshots. The generated memos were discussed and refined until a Cohen's kappa greater than 0.9 was achieved. We then clustered memos until salient themes were conceptualized and report our findings in the following section.

\section{GLAZE MATERIAL RELATIONSHIPS}

To structure the discussion of our results and provide a design framework for developing deeper material relationships, we grouped themes identified through our contextual inquiry into one of three categories: (1) factors that drive creative choices (Provocations), (2) dimensions that a practitioner navigates during a creative process (Wayfaring Dimensions), and (3) strategies uses to engage in creative sensemaking (Sensemaking). This categorization is used to describe how the different roles of the materials, tools, and environments influence a practitioner's creative activity (Figure 2). The different trajectories from provocation to sensemaking serve to represent how a creativity support tool can engage or sustain a user in material inquiry. While constructed from the glaze-practitioner relationships encountered in our contextual inquiry, many of these trajectories are portable to interactions with digital and physical materials discussed in Section 5. To protect the confidentiality of our informants, we present our observations using pseudonyms.

Ceramics Terminology. In our descriptions, we elected to retain technical ceramic terminology to maintain focus on our observations. We define only the necessary terminologies needed to understand the context behind our informant's quotes: Foremost, when a practitioner creates a ceramic artifact, they first form the artifact from unfired clay. Clay has a variety of compositions known as clay bodies. Once a clay body has been shaped into a form, it is then shelf dried in a controlled environment or it can be reconstituted with water back into a malleable clay. Once dried, a piece goes through an initial bisque firing which turns it permanently into a ceramic. Ceramicist use a temperature scale with a unit cone, abbreviated $\Delta$, ranging from $\Delta 08(955 \mathrm{C}$ or $1751 \mathrm{~F})$ used for bisque firing to $\Delta 10\left(1305^{\circ} \mathrm{C}\right.$ or $\left.2381^{\circ} \mathrm{F}\right)$ for porcelain clay bodies. In this state, the ceramic is highly absorbent (since all water in the clay was removed during the firing) and has a microstructure similar to a sponge. Ceramicists then apply paint-like glazes, which are either hand-mixed from chemicals or bought from commercial manufacturers and applied through a variety of application techniques including dipping, brushing, and spraying. Many glazes contain large amounts of silica, which during the final firing vitrifies and gives ceramics their glossy glass-like appearance and their functional impermeability to liquids. Every clay and every glaze behaves differently based on its firing schedule, or the changes in temperature from heating to cooling that occur over several hours.

\subsection{Provocations}

In contrast to anthropocentric terms like inspiration, the term provocation is used to describe the intrinsic or extrinsic motivators that drive a practitioner to engage in creative activity - in this particular context, the stage before a glaze is conceptualized or decided 
upon. Many of these motivators materialized as boundary objects, or physical objects used to transfer knowledge and underscores the force that non-human actors like materials, tools, and the environment have on creative decision-making. We present these actors by their saliency in influencing creative decision-making.

4.1.1 Environmental Drivers. Environmental drivers, or the selection of a glaze influenced by a practitioner's surroundings, altered how our informants chose which glazes to use and maintain in their spaces. These environmental actors were actively controlled by the ceramicists in the arrangement of artifacts in their studios.

Several informants sampled, or drew directly from elements in their physical environment. Edison and Seneca both described the purposeful placement of their studios next to nature. For Paul, participating in artist-in-residence programs around the world served as a means of defamiliarizing his environment.

Paul [my process] changes so much with time like an ongoing revolution ... I was in Japan last year doing an artist-in-residence and the chemicals and recipes were so different.

For production potters, their environments were actively constructed to serve as galleries of finished artifacts they had produced over the years that could be readily referenced and shared (Figure $3 \mathrm{~A}$ ).

Ruth Every time I have a glaze class, I go [to my studio's store], grab a finished sample of every combination of glazes I have and put it [in front of my class] and label them. [My students] can ... see what a finished piece will look like.

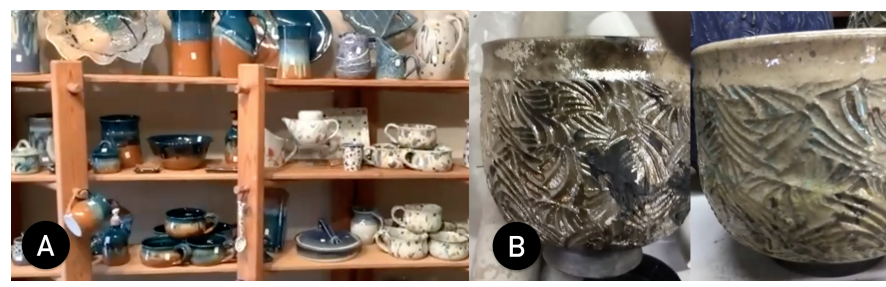

Figure 3: A) Ruth's storefront serves as a gallery of glazing techniques and choices for her students, B) Edison's Raku fired mugs are glazed using the ashes of combustible materials; ashes are removed from a mug (left) to reveal permanent coloring (right).

In addition to galleries of finished artifacts, our informants also curated intermediate artifacts in their studios. As part of a productioncentered practice, Ruth worked in large batches which required her to maintain an inventory of large buckets of glaze that she kept within hand's reach (Figure 1A). Leila, who similarly worked in batches, kept a pegboard of all the active clay bodies and glaze combinations as small keychain tokens that she would use to compare and contrast different glaze colors (Figure 1B).

Since sampling draws from the immediate environment, this method benefits from a shifting environment such as within communal studios or during prolific periods of activity. For a newcomer, the shared studio is central to this mode of engaging in creative activity; however, each gallery "system" was controlled by the original maker, limiting their value to outsiders. While all the studios we encountered encouraged collaboration, accessing information through sampling was dependent on having access to the original maker of the artifact.
Social transfer, or informing creative decisions from a practitioner's social environment, was prominent in how production potters and instructors elected glazes. Informants reported being influenced by current trends on their ceramics Facebook group, inperson community suggestions, word of mouth from their peers, or direct requests from students or customers. For production potter Ruth, the shifts in her store's inventory shaped her decisions, regularly accepting customer suggestions that did not fit her personal aesthetic.

Social transfer was a glaze election method that was actively resisted by our informants, often coupled with a feeling of "giving in" to someone else's personal preference:

Paul If there is a glaze that I do not like, or I do not think is working that well, or if I get a lot of requests from students telling me they really want a green glaze and we do not have a green glaze, only then will I add one.

Leila I don't do a lot of custom orders either. I'll do orders for people who [want my glaze design on a different clay form].

I can do that, but I'm not going to do something that's like,

"well, I like this design, but I wish it was green."

As an expert amateur, Seneca did not produce enough ceramic work to warrant mixing her own glazes; instead, she found value from community suggestions by her local ceramic supply vendor; for many of our informants, these storefronts were a major source of how information is disseminated within the ceramics community. For ceramicists from research backgrounds, openendedness community requests drove them to test under-explored glaze chemistries.

While social transfer is an artifact of how a practice is situated as an economy, we found that it had the most value when it originated from within the community of practice [11]. All ceramicists reported being active contributors and consumers of Facebook groups; these communities were important for practitioners to expand their creative inquiry and gain a sense of belonging. This form of glaze provocation leveraged the social mechanisms that are a part of legitimate peripheral participation [21], allowing newcomers to gain entry as hobbyists and gradually identify with the larger ceramics community.

4.1.2 Process Drivers. Although informants followed different creative processes, each process formalized how creative decisions were made, providing structure to their creative exploration. Material drivers, which many ceramicists followed as a result of their academic studies, motivated them to allow different material expressions to highlight a glaze's chemical or reactive properties. Navigating this design space of effects evolved as new glaze formulations were introduced into their practices. Certain glazes require special treatments and handling in order to achieve the desired outcome, which inadvertently affects other decisions. For ceramic engineer Paul, his creative inquiry focused on purposefully leveraging the typically unintended effects of glaze to crack or crystallize.

Paul [Crystalline glaze] is a very specific technique and glaze that works best on certain surfaces and certain forms. I will specifically design a form with that glaze in mind.

While typical glaze processes require several hours of firing, some glazing practices are designed to foreground these material 
actors and provide immediate results. Studio potter Edison and his students actively engaged in Raku glazing, a firing technique where rather than waiting for a kiln to cool, ceramic pieces are removed while hot and enveloped in combustible materials that produce unexpected colorings on the ceramic surface (e.g., banana peels, hair, eggshells, bacon, wire) (Figure 3 B).

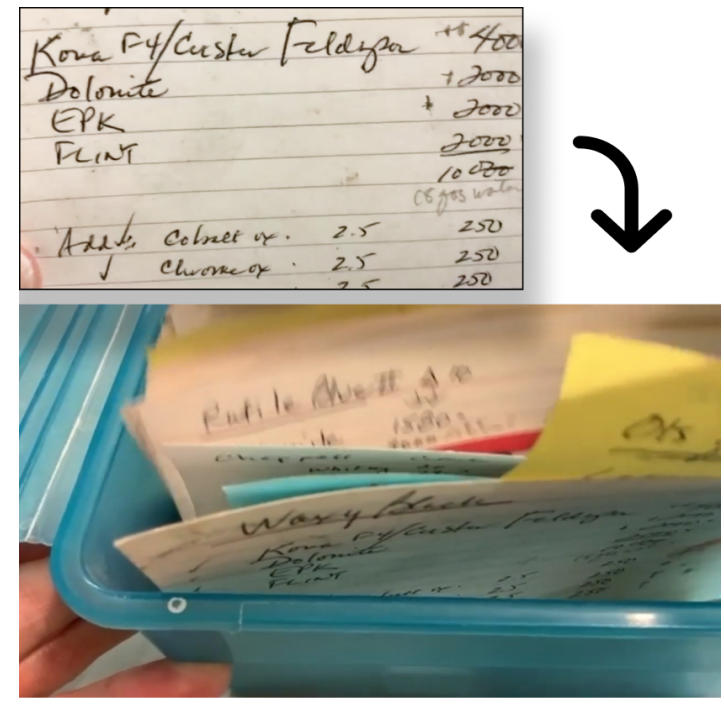

Figure 4: Ruth's recipe box contains glaze recipe cards maintained over a few decades - the cards are hand-written and updated occasionally. 'Bad' recipes are destroyed.

All informants valued replication of established glaze recipes for driving their creative inquiry, especially since they could engage with a glaze without "going into the science of it". Recipes were the primary method of transferring glaze knowledge. Although prescribed, our informants felt they were more "in control over every aspect of their process" when working from dry chemicals in contrast to buying manufactured glazes. These recipes had been shared for years among the different studios, peers, and resources they had encountered in their personal practice (Figure $4 \mathrm{~B}$ ).

Others, like Jackson, who runs a popular glaze chemistry workshop, regularly engaged in systematic experimentation, or following a plan or procedure to motivate decisions of what is made, how it is observed, and the ways that it is documented. Following a systematic plan allowed Jackson to engage prolifically in creating novel glazing effects and a wide social media following. Notably, engaging in this process minimized the need to reflect on success and failure:

Jackson For us, it is more about trying to figure out the parameters of any glaze ... we do not put any expectations on the result, we just want to see what happens when we cover our chemical bases and look with a systematic parameter, so if we see something that is of interest we take that and refine it and do it again.

For ceramists that primarily engaged in experimental practices, our informants described a sense of pride and ownership intertwined with making a glaze from scratch. The offloading of creative decisions to process was beneficial in engaging in a prolific practice that provided more opportunities for sensemaking.
4.1.3 Theory-Driven. Lastly, theoretical drivers arose outside of the context of making. Most common was the need to consider function, specifically whether a ceramic would serve an artistic or decorative role (e.g., a sculpture, matte or glossy finish), a functional use (e.g., a food-safe mug), or something in between (e.g., a decorative vase that holds water). Rarely was the process of satisficing function straightforward, requiring complicated and meticulous thinking:

Seneca If it is a piece that people are going to touch a lot, like a mug, the glossy just feels a little better. If it is something that is more of a display or sculpture, I like the matte since it looks really cool because it looks store-bought Pier One. I need to figure out the function before I go into color.

Selecting a glaze from its functional required practitioners to "live" with their object and understand how that object transformed over time. This formed a deeper relationship with the material that extended past its making or form-giving state and considered the artifact's life cycle. For instance, taking into account where the object failed (e.g., dishwasher, fingerprints), where it thrived (e.g., as a spectacle of an object), and how it changed over time (e.g., cultural moments, fads). Extending a material relationship based on function required our informants to become active and varied users of their artifacts.

\subsection{Wayfaring Dimensions}

From the initial clay form to the final glaze firing, various formal properties play a role in the final outcome of a ceramic piece. We identified the properties that our informant ceramicists consider when glazing and leverage Ingold's wayfaring to describe an "intuition of action" where practitioners use past experiences (e.g., recovering from errors, mistakes, and failures) to sense actions of resistance or opportunity so as to navigate the possible forms of a material [17]. We consider both material interactions with each other, with the way they are applied and handled, and the ways in which kiln-firing transforms them into iconic ceramic artifacts.

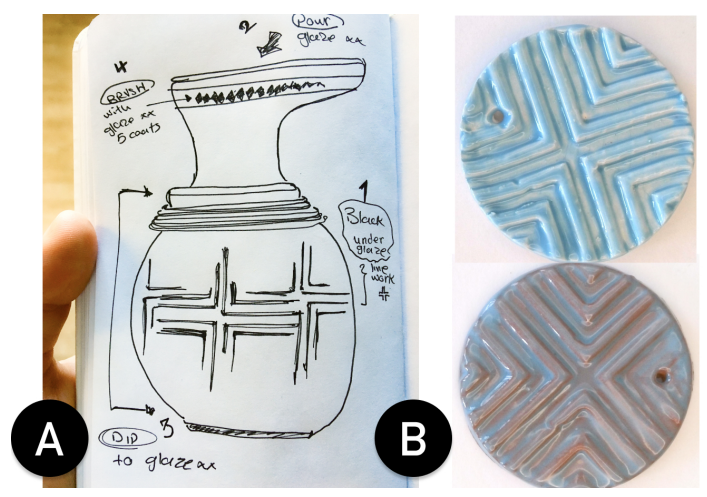

Figure 5: a) An annotated sketch used by Paul's students to plan their glazing process. The sketch denotes the ordering of steps, methods of application, and glaze names; b) the same glaze (AMACO TP-20) is applied using a brush to a textured stoneware clay body (top) and an earthenware clay body (bottom), producing different visual effects. 
4.2.1 Clay Body and Firing Condition. A clay body refers to the type of clay being used (e.g., earthenware, stoneware, or porcelain). Each clay body and each glaze requires specific firing conditions, which must match to create a functional piece. Aside from the technical firing collisions, glazes will look and feel different depending on the clay body (Figure 5 B). For Seneca, choosing her clay body was based on its ability to highlight a desired glaze characteristic.

Each clay is influenced by a variety of firing conditions including the cone fire, heating cycles, and kiln type (gas, electrical, salt, wood), weather, levels of oxygen, or distribution of thermal mass within a kiln. These firing conditions are especially important to glaze-clay body interactions since some glazes exhibit different properties at different firing conditions (e.g., running, expressing different colors, crystalizing, cracking, or crazing) (Figure 6 B). As Paul describes, "wood firing [creates] ash that flys around the kiln and attaches itself to the clay, and creates its own glaze" (Figure $3 \mathrm{~B})$. Many of our informants assign designated firing conditions based on the final functionality of the piece.

Due to the cost of firing, many ceramicists batch ceramic artifacts to fire at once. Gas kilns, due to their size and price, are mostly limited to formal studio spaces, while electric kilns are more portable to home studios. Being able to experiment with diverse methods of firing is one of the shared experiences amongst our informants, which they explained drives the widest range of glaze expressions. For new students, access to these facilities remains a challenge and limits their ability to experientially develop this knowledge. Although this information can be accessed from written or video resources, subtle details like the behavior of everyday organic materials remain largely an exploratory practice.
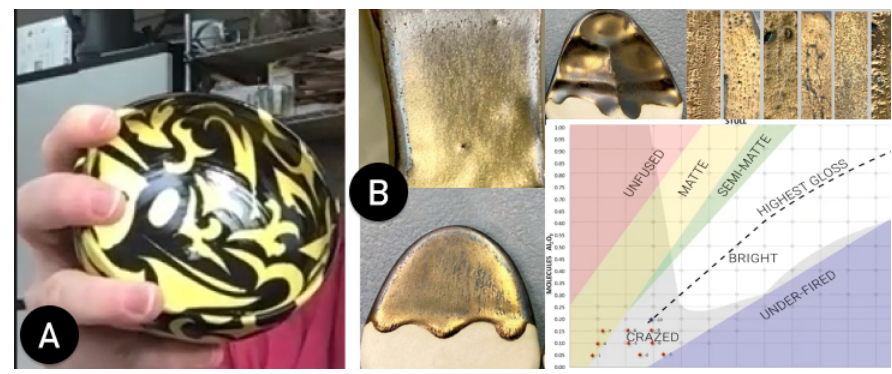

Figure 6: a) Seneca uses a masking technique to apply a black glaze over a yellow underglaze - the mask is burned away during firing, b) a Unity Molecular Formula (UMF) stull chart is used by Jackson to explore variations of an iridescent gold glaze.

4.2.2 Glaze Application. A central glazing design space is controlled by how the glaze is applied onto the clay body and includes techniques such as pouring, dipping, brushing, and spraying. These techniques are often combined, or several are used on a single ceramic artifact but remains a tacit skill to replicate:

Seneca The [hardest part of keeping track of a glaze] is finding out how the glaze was applied. If I paint with a paintbrush, the glaze can look very different than if I had poured it on or dipped it into a big bucket. It would be helpful if an artist could say [specify in a digital record] - I poured that glaze "very" thick to get the results.

Some practitioners use novel application methods developed as a result of their personal practice. As a modernist designer, Leila uses a needle-tipped applicator bottle and a catch-all plate to "sketch" her glaze design on her pieces. For Seneca, her sketchbook drawings are transferred to her designs using a "sticker" masking technique which is burned away during firing (Figure $6 \mathrm{~A}$ ).

Glaze location coupled with the effects of gravity and texture was an important factor in controlling how different glazes behaved. Several ceramicists intentionally used the location on a form to leverage a glaze's propensity to run. While often a negative effect (i.e., leading to a glaze running down and fusing to a kiln shelf), it was sometimes used to mend and fuse broken pieces or applied on the inside walls of containers. Grassroots innovations have become privy to the running glaze error; Jackson regularly uses popsicleshaped test keys (Figure $1 \mathrm{C}$ ) designed to catch glaze runoff and prevent possible fusion problems. When running over textures, glazes will thin and reveal features of a texture - this technique required careful planning to achieve a desirable outcome. As Edison describes, "If I am doing a lot of texture, I want a glaze that will enhance the texture. Not take away from it."

4.2.3 Glaze Chemistry. Glaze chemistries are used similarly to a cooking recipe, composed of ingredients containing silica, flux, and oxides. The chemistries have a tight link to firing conditions - factors such as color, thermal expansion, melting temperatures, hardness are dependent on the specific amounts of oxides within a glaze. Jackson, a glaze researcher, regularly studies these relationships to uncover new glazes (Figure 6B).

Jackson We were looking at some of the variables that control that gold color. Some [of these iterations] have more gold, but the gold dissipates as we move through different chemistries. We're seeing if it gets more intense or less intense and figuring out what those overall defining parameters are.

Glaze chemistries were used to gain a scientific understanding of the material. Edison and Jackson both controlled their kiln and studio environments and isolated the specific glaze ingredients that affected a target glaze expression. Others like Seneca and Ruth took a more experiential approach to unlock new glazes. Both groups learned to predict and anticipate a glaze's behavior through studying its chemistry. Because of the many different parameters, firing conditions, and material interactions, theoretical discussions were limited compared to the larger space of glaze wayfaring dimensions.

\subsection{Sensemaking Strategies}

Unlike raw clay that can be reconstituted and reused, firing clay transforms it permanently into a ceramic. Without being able to recover the ceramic, our informants developed different sensemaking strategies to be able to extract new information on creative trajectories to follow, avoid, or overcome. We describe these sensemaking strategies in the context of our informant's personal practice and their teaching practice.

4.3.1 Serendipity. Race et al. [30] describe serendipity as "the happy accident of discovery" that is more than just blind luck, but a 
phenomenon that can be influenced and cultivated through actively searching for serendipitous opportunities. These sites for serendipity arose naturally from the unpredictable and temperamental act of glazing. For all of our informants, this unpredictable quality in ceramics was openly accepted and cherished part of ceramics work, especially when coupled with the anticipation from leaving a glazed object overnight to fire followed by the great reveal from opening a kiln. While ceramicists developed more control and knowledge of how glazes react over time, they still maintain elements of their practice open for serendipity. Edison, with more than 51 years of experimenting in ceramic and glaze chemistry, found value in ceding control to the glaze:

Edison I made these pitchers [two different colored regions separated by a line] using the texture of the pot itself. I can [control] the two colors, but I let the line overlap for the glaze to do its magic. That part [the line] I cannot control, because when they bleed, you can only control so much ... that's the fun part about it.

Across all informants, we found a common practice of collecting leftover glazes in a common container. This "mystery glaze" acted as a functional way to reduce waste and also established an opportunity to allow for unexpected results. Sometimes, the mystery glaze would produce "a really beautiful glaze" (Paul), while for others, it would "eventually arrive at some sort of green"(Seneca). Notably, the contents of a mystery glaze were never documented and contributed a playful role in shared studios. Serendipity was used by ceramicists to add excitement and wonder to their work. While this form of sensemaking is more difficult to be used to refine the understanding of wayfaring dimensions, it instead invited practitioners to encounter new unknowns and seed future material investigations that further develop their material relationships.

4.3.2 Trial and Error. Trial and error refer to a mode of problemsolving where a person learns by trying new strategies and combinations and rejecting errors until an adequate solution is found. We encountered this behavior resulted in a lack of external documentation amongst our informants; instead, practitioners relied on their ability to remember their choices, processes, and outcomes. This lack of documentation worked well in their personal practices, where they were able to "complete an idea" by iteratively adjusting glaze recipes or processes. However, within the ceramics classroom, our informants regularly encouraged their students to create glaze keys, or sacrificial tiles used to test out a glaze (Figure 7). While only Leila actively used this strategy in her personal practice, others like Edison found the act of documenting glaze tiles futile since the record depended on a reliable and consistent source of materials. Glaze chemicals, especially colorants, are derived from mining sites which were liable to change over the years. While glazed and fired artifacts also served as a type of glaze key, our informants rarely referred to these records to make sense of their glazing results.

Ruth I remember it by heart. I can even tell [what my students] use. I tell them to write it down, but they never do.

This form of sensemaking often resulted in our informants becoming the gatekeepers of information; their reliance on their personal memory often led to common "errors" being accepted as a natural part of doing ceramics.
Edison This piece is double-dipped in different glazes - here you see the overlap of one Shino glaze with another Shino glaze. You could keep them separate, but it's more like an artist when they are painting - you understand that two colors will react, you remember that, and store it in your brain. But the mistake [i.e., accidentally overlapping colors] will occur again from stupid mistakes. Sometimes it is a mistake, while other times I like the mistake and do it again.

Sensemaking through trial-and-error was a common strategy for informants that taught introductory classes, encouraging students to make many samples or drive their glaze selection from personal interest served as a method of developing a practice that allowed them to regularly interact with glazes and build their understanding of the material.

This learning strategy was predicated on the lack of utility in external documentation, which in turn supported uninterrupted workflows with more continuous and frequent interactions with glazes. While glaze keys were an acknowledged "best practice", the reality for these experienced ceramicists was to leverage their memory for bookkeeping. Occasionally they used fired scraps or finished pieces as boundary objects for instruction, but rarely for their own personal practice. Errors that resulted from lapses in memory were reframed as sites for serendipity.
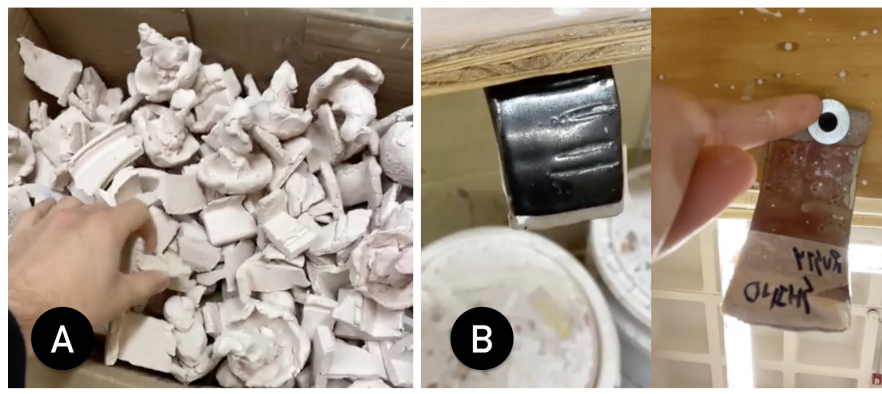

Figure 7: a) A bucket of scrap pieces in a university ceramic studio, ready for students to use for glaze testing; $b$ ) test tiles are screwed to the bottom of the shelf as a permanent record in the studio.

4.3.3 Indexical Records. Our informants generated a variety of temporary records, ranging from composition book sketches and notes, annotations on recipe cards, and collections of glaze keys. However, this class of records was rarely referenced. We draw from the concept of indexicality in photography to describe this behavior - the record served primarily to capture a moment in time and to attest to its occurrence [15]. In Paul's classroom, students made keys from scrap pieces and labeled the bottom of their keys with their initials and an identifying number (Figure 7 A), but these keys would often remain abandoned or misplaced over time. Using glaze keys in the studio required making them permanent fixtures, such as Paul screwing keys alongside glazes on a storage shelf to guarantee their safety and availability (Figure 7B). Others like Seneca would use the temporary intention of glaze keys and misfired objects to attend to the emotional labor of ceramics work, accumulating them in a bucket and, over time, breaking them on stressful days. 
Rather than being used to directly maintain information, indexical records served primarily as a memory aid. This type of sensemaking benefits from creating artifacts that are able to trigger and recreate memories of processes and outcomes. For our informants, their recollection of these artifacts is reinforced by repetition, which places a newcomer at a disadvantage. While some efforts within the ceramics community aim to standardize the ways that information is recorded (e.g., glazy.org), indexical records remain the most pragmatic method that material relationships are developed

4.3.4 Rigorous Records. While indexical records were abundant in the studio, some informants began to develop rigorous records of their experiments, treating every fired piece as a point of reference to guide future glazing iterations.

Physical records, like glaze keys, are difficult to document since writing or labeling them directly is cumbersome, usually through an underglaze pencil or texture stamp. For Leila, these marks detract from the aesthetic value of an object. She instead used a textured pattern to pair a sacrificial key with a finished artifact and encode the key with pertinent information. In her communal studio, she regularly created many glaze keys to gift to other potters. She would display her collection prominently in her studio and often use it to drive her design decisions (Figure 1B).

Leila I'll be making something a year from now, and [remember that] I tested that already. I'Il dig through my test tiles, and I'II find the test tile. I'll [use it to figure out if] it worked or didn't work [against] what is in my mind ...

Computational technologies in the pottery studio were different in nature from the material they work with; however, adding technology into those spaces was not a foreign endeavor but was consistently found to be incompatible with physical workflows.

Jackson Our assistants have a hard time tracking what they have done on the monitor. We decided to stick with paper because you literally just cross off and know what was completed

All acknowledged the difficulties of dust and clay in maintaining these technologies and the need for reliability in retrieving information as needed.

Jackson Dust is continuously a problem. We have monitors and mice in hidden workstations around there, and we have equipment that uses computers, but the dust is the real issue.

Our informants developed workflows for overcoming these challenges, leveraging digital record-keeping forms like Excel-based documents or PowerPoint presentations (Figure 8); these records were often used to discover relationships between formal properties, plotting relevant data into charts, and computing stoichiometric calculations using the Unity Molecular Formula (UMF), or Stull chart, which have become the standard method of understanding glaze behaviors through community-driven recipe repositories like glazy.org [1]. This method of documentation was most commonly used by informants that engaged with glaze chemistries or whose glaze decisions were driven by systematic experimentation. More experimental practitioners like Edison aimed to rigorously control the firing condition, for example, by retrofitting his kiln with sensors to document temperature, oxygen level, humidity, and other environmental factors. This documentation empowers him to

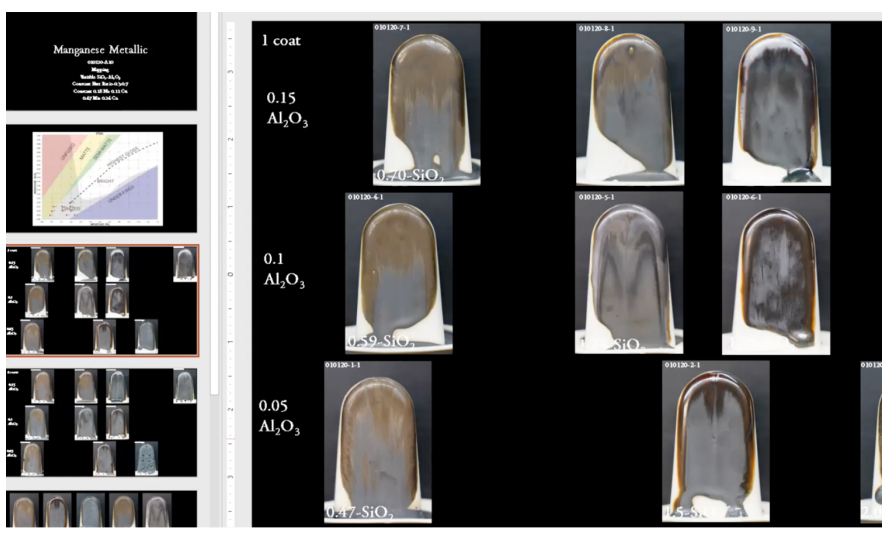

Figure 8: PowerPoint slides are used to communicate Jackson's parametric exploration through several batches of a manganese metallic glaze recipe.

gain more control over his process and eventually gather enough data to automate this stage.

Jackson prioritized maintaining the veracity of his records using a combination of digital documents (a photo rig and color correction routine) and physical documents (bagging, labeling, and storing all test tiles). This meticulous record-keeping system evolved throughout Jackson's practice: he found that previously arranging records by color, author, or other formal property never functioned well for retrieving information - instead, his current system simply annotated records by time; this allowed the batches of his systematic experiments to stored in the same bin. He found that he could more readily recall the events and creative inquiries that were occurring during different months across multiple years.

While glaze recipe repositories aim to enable grassroots contributions to advance the space of glaze expressions, we found that the idea of a "rigorous record" carried different meanings across practitioners. For example, Jackson was cautious of using other ceramicist's results due to potential and uncontrollable deviations in how the glaze was prepared or from the differences in the firing environments between two potters. The shareability of records remains conditioned on a practitioner's trust in a similar environment, process, and background of other ceramicists.

\section{RECOMMENDATIONS FOR DESIGN}

Although synthesized from a domain-specific practice, the material relationships we encountered from studying glaze relationships can offer insights on how interaction designers can support other material practices that carry similar economies of time (e.g., awaiting a day-long print from when 3D printing thermoplastics, waiting for silicone and resins to cure, or growing biomaterials like mycelium) or complexities of material expression (e.g., the breath of surface expressions from dyeing, perforating, engraving, or carving leather). In practices with week-long and centralized workflows like ceramics, the difficulty of engaging with a material becomes more pronounced. These insights can specifically address how creativity support tools can sustain a practitioner in practice that would otherwise require a formal apprenticeship or intrinsically motivated years of practice [18]. 
The glaze epoch, a term we use to refer to the lifelong relationships with materials that have formed from those years of practice, revealed distinct ways that practitioners are (1) provoked to engage in a material encounter, a reciprocal relationship where "the material is the target of and partner in a process which is enabled by this crafter-tool dynamic" [27], and (2) how the information the material communicates back to the practitioner is used to seed future creative inquiry.

\subsection{Provoking Material Encounters}

Interaction design has been conceptualized as a bricolage practice, differing from a reflective conversation with materials by instead constituting a non-hierarchical "in situ structuring of events through material assemblage and modification" [44]. In our contextual inquiry, we saw principles of bricolage in how our informants constructed their environments to allow for new connections (Seneca's glaze key wall), provide access to creative directions to students (Ruth's storefront-teaching studio), and influence material expressions (Leila positioning a studio next to nature).

Externalize non-visual dimensions to diversify bricolage practice. While we might arrange the physical materials, tools, and artifacts in the bricoleur's space, this practice is tied to the sensory abilities of the body, which biases the type of associations formed to visual material dimensions. Instead, elevating the saliency of haptic and conceptual material dimensions can enhance the benefits of bricolage. For instance, how might the ways glazes are applied be brought to the same level as the physical properties of glazes? We encountered ceramicists referring to conceptual applications ("I brushed the glaze on") that carried significant tacit information ("brushed thick") difficult to represent as words or diagrams. In this situation, creating records like video collages of brushing motions playing in the ambient background can help diversify the type of perceptual feedback and creative dimensions available to the bricoleur.

Create utility from failure spaces to encourage surrendipity. Within the glazy.org community, the ability to chart and systematically explore chemical variations of a glaze recipe altered the criteria for success and failure of a piece. Every experiment had value, serving to annotate a point in the Stull chart (Figure 6 B) and better understand how different chemical compositions affect the expression of a glaze. On the other hand, this two-dimensional space provided sites for serendipity, asking ceramicists to explore undesirable spaces where the glaze might become matte, craze, crystallize, under-fire, or under specific conditions achieve a bright, high-gloss finish. We argue situations of serendipity elicit an "ambiguity of relationship", creating a situation where the ceramicist can apply a "deep personal projection of imagination and values onto a design" [12] so as to consider how these undesirable effects. Interaction design may benefit from purposefully building utility from failure spaces such that a practitioner is trained to examine and recast ambiguity; in the case of 3D printing, failed prints could be decomposed into useful scraps or used to mark the extrusion parameter space - in clay 3D printing, we already encounter "failure" conditions like over-extrusion being used as a decorative element in 3D-printed ceramics.

\subsection{Charting Material Knowledge}

Standardize annotations to provide waypoints. Several informants credited their understanding of different material relationships to the ways Big-C ceramicists represent their creative explorations. Like most material practices, the space of material dimensions was too large to consider - these representations served as lenses into a particular person's style. We see value in standardizing the visual representations of form and process to support plural material practices to co-exist. For instance, a standardized representation specific to glaze application dimensions can reduce frictions in exploring exposed dimensions (e.g., a ceramicist that only has applied single coats sees "number of coats" as a formal dimension), breaking out of prescribed dimensions (e.g., the standardized representation does not acknowledge applying glaze to large geometric holes), or mixing wayfaring dimensions (e.g., applying a different glaze chemical composition between layers). For biomaterial practices where the visibility of dimensions is similarly limited by observability, these standardized forms can provide a smaller space of actions to encourage exploration (e.g., the type of growth medium for mycelium: agar, sugar, oats, organic material) or to understand where one is within their personal creative development.

Patinate material dimensions to create value. Part of the richness of glazes was the lack of control across every dimension of the material. Ceramicists embraced this lack of precise control and the fundamentally unique results they would receive after each glaze firing. Within Raku glazing (e.g., Edison's mugs - Figure 3 B), combustible materials like banana peels are used to source colorant chemicals (e.g., potassium) to color ceramic pieces - this practice is used to more saliently capture the trace effects of environmental actors and create a sense of terroir, grounding the pieces in the environments in which they were produced. For digital materials composed by a designer, this suggests an opportunity to release control of the material, allowing probabilistic and environmental elements to influence the outcome of a design. As has been encountered in material practices with leather [28, 43], concrete [16], and data modeling [38], these patinations serve as mechanisms for materials to communicate affordances and impart value through the uniqueness of the expressed form.

\subsection{Synthesizing Material Information}

Obscure and dramatize process to create wonder. While all ceramicists had significant experience working with glazes, they all openly acknowledged that there are some external variables that can never be controlled, likening this relationship to "an ordered chaos" (Ruth). Both Edison, through a sensor retrofitted kiln, and Jackson, through systematic experimentation, had developed workflows to further remove these improbabilities, but both describe their passion for ceramics from the unexpected turns that have a proclivity to occur. As motivated by Devendorf et al. [7], supporting sites for serendipity to occur can support a morphogenetic method of making - documenting or improving the visibility of these material relationships would erode this important activity. Glaze epochs suggest purposefully creating sites for mystery and surprise by obscuring or dramatizing the process can drive the interpretation 
of these incidents as happy accidents (e.g., mystery glaze buckets, the inability to observe a glaze being fired).

Force moments for projection to seed creative inquiry. For other physical or digital materials, creating unexpected outcomes is already a reality; however, the challenge instead entails how to improve a user's proclivity to attend to these ambiguous relationships. The glaze epochs observed suggest that economies of material (e.g., the amount of excess glaze leftover or the cost of raw materials) and economies of time (e.g., the effort needed to remove a failed glaze piece from a fused shelf) helped to create conditions for pause. When considering weaving practices where fiber is abundant, creating artificial scarcity of yarn (e.g., by adding resistance to an overused spool or limiting the number of times a warp pattern can be used) can create moments for reflection, especially as means to consider alternative material dimensions.

Use wearable and tangible user interface to document and share process. Like many other material practices, the ceramics environment makes it difficult for practitioners to document their process. We encountered that many sensemaking activities benefit from this lack of documentation. However, for many of our pro-C informants, their knowledge of glaze interactions limited a student's access to this information to the moments they were available in the studio. Wearable technologies have been proposed as a solution for bringing technologies into "harsh environments" in outdoor field studies [29] that could serve ceramic and other material studio spaces. In shared spaces such as studios, allowing multiple users to build information collaboratively is important both as a learning technology and as a means of improving the replicability of the creative process. One opportunity lies in using passive sensing technologies like RFID, magnetic labeling, or NFC tags to associate the variety of existing physical records created in the environment to become embedded with metadata describing different artifacts. For example, these passive markers would allow a practitioner to associate paper sketches, recipe cards, or the glaze containers themselves with each other and allow other makers to access this information in a shared environment.

Support associative tagging to build creative connections. While glazes have natural dimensions that support hierarchical or principled organization, retrieving information from recording systems used by expert ceramicists relied heavily on associative cues. For instance, Seneca used a composition notebook to record different glaze design decisions; these notebooks were used to track creative thought but were rarely used as a reference to use in later work. Instead, the studio "naturally" maintained the organization of the records through natural hierarchy like throwing away bad batches and their associated recipes (Ruth), having popular glazes percolate to visibility from recency of use or customer sales (Ruth), marking important information on the cover of her composition netbooks (Seneca) or through elevating tried-and-true recipes to have their dedicated 5-gallon containers in the studio classroom (Paul). This suggests that material knowledge repositories could benefit from having different qualities of permanence in records and reduce the friction required to demote or promote records into more formal representations. The differences in the organization of material records were heavily predicated on whether others would use them. This indicates an opportunity to organize personal data records, not by properties or features of the records themselves, but instead through associative cues that mark associations between artifacts (e.g., shared firings, shared creative inquiry) that better match the ways that the original maker associates information.

\subsection{Limitations}

Informants in our contextual inquiry were skewed towards practitioners that mix their own glazes; Seneca remained the only informant that used commercial glazes. Her feedback gave us an indication of how expert amateurs [20], or practitioners that do not engage professionally with a practice but are senior members of the hobbyist community, have different modes of foraging and resolving information. Since experts can easily lose sight of what it was to not know [36], we see value in expanding the scope of our inquiry to what Nicola Wood describes as the modern journeyman [47]. These journeypeople include those that serve as an intermediary between the expert and novice, having not completely internalized the tacit knowledge inherent to material practices. Observing this intermediary stage can help us understand how material relationships develop throughout a user's creative development. Conducting a large part of our site visits virtually placed limitations on what our informants chose to show us. Since ceramic studios are not generally private spaces, we found that virtual contextual inquiry allowed the informant to show us their viewpoint (figuratively and literally) and understand where they attend to in the wide breadth of stimuli present in a studio practice. As a tradeoff, many of the haptic and non-visual sensory qualities of the studio environment and practice were absent from our analysis. The study was limited to a one-hour study which influenced our ability to assess how studios change over time, especially considering the different contexts that alter creative strategies (e.g., teaching a class of newcomers, preparing for an exhibition, or after a kiln firing).

\section{CONCLUSION}

In this paper, we motivated the need for material-centric interaction design to consider relationships with materials that occur over years of practice. We described a rapid ethnography method used to synthesize a material-centric model of glazing. Through virtual studio visits of six master ceramicists with a combined 163 years of experience, we leveraged contextual inquiry to understand the tacit practices involved in making, documenting, and tracking the behaviors of glazes from kiln firing. We presented our findings through a framework the material relationships encountered into provocations, wayfaring dimensions, and creative sensmaking straegies. From this framework, we provide recommendations for foregrounding material relationships in the design of creativity support tools.

\section{ACKNOWLEDGMENTS}

We thank the informants of our study for providing us access to their space and practice and the anonymous reviewers for their valuable feedback.

\section{REFERENCES}

[1] Derek Au. 2020. glazy.org. https://glazy.org/ 
[2] Bahareh Barati, Elisa Giaccardi, and Elvin Karana. 2018. The making of performativity in designing [with] smart material composites. In Proceedings of the 2018 CHI Conference on Human Factors in Computing Systems. 1-11.

[3] Hugh Beyer and Karen Holtzblatt. 1999. Contextual design. Interactions 6, 1 (Jan. 1999), 32-42.

[4] Amy Cheatle and Steven J Jackson. 2015. Digital entanglements: craft, computation and collaboration in fine art furniture production. In Proceedings of the 18th ACM Conference on Computer Supported Cooperative Work \& Social Computing. 958-968.

[5] Ricky Chen, Mychajlo Demko, Daragh Byrne, and Marti Louw. 2021. Probing Documentation Practices: Reflecting on Students\&\#x2019; Conceptions, Values, and Experiences with Documentation in Creative Inquiry. In Creativity and Cognition (C\&amp;C '21). Association for Computing Machinery, New York, NY, USA, 1. https://doi.org/10.1145/3450741.3465391

[6] Victoria Clarke and Virginia Braun. 2014. Thematic analysis. In Encyclopedia of critical psychology. Springer, 1947-1952.

[7] Laura Devendorf, Abigail De Kosnik, Kate Mattingly, and Kimiko Ryokai. 2016. Probing the potential of post-anthropocentric 3D printing. In Proceedings of the 2016 ACM conference on designing interactive systems. 170-181.

[8] Kristin N. Dew and Daniela K. Rosner. 2018. Lessons from the Woodshop: Cultivating Design with Living Materials. In Proceedings of the 2018 CHI Conference on Human Factors in Computing Systems. Association for Computing Machinery, New York, NY, USA, 1-12. http://doi.org/10.1145/3173574.3174159

[9] Nir Dick, Naama Glauber, Adi Yehezkeli, Moran Mizrahi, Shani Reches, Maiayn Ben-Yona, Anna Carmi, and Amit Zoran. 2018. Design with Minimal Intervention: Drawing with Light and Cracks. In Proceedings of the 2018 Designing Interactive Systems Conference (DIS '18). Association for Computing Machinery, New York, NY, USA, 1107-1120. https://doi.org/10.1145/3196709.3196814

[10] Shreyosi Endow and Cesar Torres. 2021. "I'm Better Off on My Own": Understanding How a Tutorial's Medium Affects Physical Skill Development. In Designing Interactive Systems Conference 2021 (Virtual Event, USA) (DIS '21). Association for Computing Machinery, New York, NY, USA, 1313-1323. https://doi.org/10.1145/3461778.3462066

[11] Gerhard Fischer, Elisa Giaccardi, Hal Eden, Masanori Sugimoto, and Yunwen Ye. 2005. Beyond binary choices: Integrating individual and social creativity International journal of human-computer studies 63, 4-5 (2005), 482-512.

[12] William W Gaver, Jacob Beaver, and Steve Benford. 2003. Ambiguity as a resource for design. In Proceedings of the SIGCHI conference on Human factors in computing systems. 233-240.

[13] Geoffrey Gowlland. 2015. Unpacking craft skills: What can images reveal about the embodied experience of craft? Visual Anthropology 28, 4 (2015), 286-297.

[14] Camilla Groth, Maarit Mäkelä, and Pirita Seitamaa-Hakkarainen. 2015. Tactile augmentation: A multimethod for capturing experiential knowledge. Craft Research 6, 1 (2015), 57-81.

[15] Tom Gunning. 2004. PLENARY SESSION II. Digital Aestethics. What's the Poin of an Index? or, Faking Photographs. Nordicom Review 25, 1-2 (2004), 39-49.

[16] Linda Hirsch, Beat Rossmy, and Andreas Butz. 2021. Shaping Concrete for Interaction. In Proceedings of the Fifteenth International Conference on Tangible, Embedded, and Embodied Interaction. 1-11.

[17] Tim Ingold. 2013. Making: Anthropology, archaeology, art and architecture. Routledge.

[18] James C Kaufman and Ronald A Beghetto. 2009. Beyond big and little: The four c model of creativity. Review of general psychology 13, 1 (2009), 1-12.

[19] Irni Eliana Khairuddin, Corina Sas, and Chris Speed. 2019. BlocKit: A Physical Kit for Materializing and Designing for Blockchain Infrastructure. In Proceedings of the 2019 on Designing Interactive Systems Conference (San Diego, CA, USA) (DIS '19). Association for Computing Machinery, New York, NY, USA, 1449-1462.

[20] Stacey Kuznetsov and Eric Paulos. 2010. Rise of the expert amateur: DIY projects, communities, and cultures. In Proceedings of the 6th Nordic conference on humancomputer interaction: extending boundaries. 295-304.

[21] Jean Lave and Etienne Wenger. 1999. Legitimate peripheral participation. Learners, learning and assessment, London: The Open University (1999), 83-89.

[22] Jessica Lingel. 2016. The Poetics of Socio-Technical Space: Evaluating the Internet of Things Through Craft. In Proceedings of the 2016 CHI Conference on Human Factors in Computing Systems. Association for Computing Machinery, New York, NY, USA, 815-826.

[23] Yilin Elaine Liu, Michael Nitsche, and Benjamin N. Sugar. 2019. Reflection on Tacit Knowledge - Effect of Providing EMG Visualization on Reflections on Throwing Clay. In Proceedings of the 2019 on Creativity and Cognition (C\&amp;C '19). Association for Computing Machinery, New York, NY, USA, 619-625. https: //doi.org/10.1145/3325480.3326576

[24] Nolwenn Maudet, Ghita Jalal, Philip Tchernavskij, Michel Beaudouin-Lafon, and Wendy E Mackay. 2017. Beyond Grids: Interactive Graphical Substrates to Structure Digital Layout. In Proceedings of the 2017 CHI Conference on Human Factors in Computing Systems. Association for Computing Machinery, New York, NY, USA, 5053-5064.

[25] David R Millen. 2000. Rapid ethnography: time deepening strategies for HCI field research. In Proceedings of the 3rd conference on Designing interactive systems. processes, practices, methods, and techniques. 280-286.

[26] Martin Murer. 2018. Making Things Apart: Gaining Material Understanding. In Proceedings of the 2018 Designing Interactive Systems Conference. 497-509.

[27] Michael Nitsche and Anna Weisling. 2019. When is it not Craft? Materiality and Mediation when Craft and Computing Meet. In Proceedings of the Thirteenth International Conference on Tangible, Embedded, and Embodied Interaction (Tempe, Arizona, USA) (TEI '19). Association for Computing Machinery, New York, NY, USA, 683-689.

[28] Minna Pakanen, Kasper Heiselberg, Troy Robert Nachtigall, Marie Broe, and Peter Gall Krogh. 2021. Crafting a Leather Self-tracking Device for Pollen Allergies. In Proceedings of the Fifteenth International Conference on Tangible, Embedded, and Embodied Interaction. 1-15.

[29] Andrew Quitmeyer and Hannah Perner-Wilson. 2015. Wearable studio practice: design considerations for digital crafting in harsh environments. In Adjunct Proceedings of the 2015 ACM International foint Conference on Pervasive and Ubiquitous Computing and Proceedings of the 2015 ACM International Symposium on Wearable Computers (UbiComp/ISWC'15 Adjunct). Association for Computing Machinery, New York, NY, USA, 1285-1293. https://doi.org/10.1145/2800835. 2807926

[30] TM Race and S Makri. 2016. Introducing Serendipity. In Accidental Information Discovery. Elsevier, 1-13.

[31] Erica Robles and Mikael Wiberg. 2010. Texturing the "Material Turn" in Interaction Design. In Proceedings of the Fourth International Conference on Tangible, Embedded, and Embodied Interaction (Cambridge, Massachusetts, USA) (TEI '10). Association for Computing Machinery, New York, NY, USA, 137-144. https://doi.org/10.1145/1709886.1709911

[32] Daniela K. Rosner. 2012. The material practices of collaboration. In Proceedings of the ACM 2012 conference on Computer Supported Cooperative Work (CSCW '12). Association for Computing Machinery, New York, NY, USA, 1155-1164. https://doi.org/10.1145/2145204.2145375

[33] Daniela K Rosner, Miwa Ikemiya, and Tim Regan. 2015. Resisting Alignment: Code and Clay. In Proceedings of the Ninth International Conference on Tangible, Embedded, and Embodied Interaction (Stanford, California, USA) (TEI '15). Association for Computing Machinery, New York, NY, USA, 181-188.

[34] Hidekazu Saegusa, Thomas Tran, and Daniela K. Rosner. 2016. Mimetic Machines: Collaborative Interventions in Digital Fabrication with Arc. In Proceedings of the 2016 CHI Conference on Human Factors in Computing Systems. Association for Computing Machinery, New York, NY, USA, 6008-6013. http://doi.org/10.1145/ 2858036.2858475

[35] Kim Salazar. [n.d.]. Contextual Inquiry: Inspire Design by Observing and Interviewing Users in Their Context. https://www.nngroup.com/articles/contextualinquiry/

[36] Richard Sennett. 2008. The craftsman. Yale University Press.

[37] Toyohiko Sugiyama. 2014. Construction of a glaze database. Key Eng. Mater. 608 (April 2014), 37-40.

[38] Cesar Torres and Eric Paulos. 2015. MetaMorphe: Designing expressive 3D models for digital fabrication. In Proceedings of the 2015 ACM SIGCHI Conference on Creativity and Cognition. 73-82.

[39] Cesar Torres, Sarah Sterman, Molly Nicholas, Richard Lin, Eric Pai, and Eric Paulos. 2018. Guardians of Practice: A Contextual Inquiry of Failure-Mitigation Strategies within Creative Practices. In Proceedings of the 2018 Designing Interactive Systems Conference. 1259-1267.

[40] Cesar Armando Torres. 2019. Hybrid Aesthetics: Bridging Material Practices and Digital Fabrication through Computational Crafting Proxies. Ph.D. Dissertation. UC Berkeley.

[41] Cristen Torrey, David W. McDonald, Bill N. Schilit, and Sara Bly. 2007. How-To pages: Informal systems of expertise sharing. In ECSCW 2007, Liam J. Bannon, Ina Wagner, Carl Gutwin, Richard H. R. Harper, and Kjeld Schmidt (Eds.). Springer, London, 391-410. https://doi.org/10.1007/978-1-84800-031-5_21

[42] Vasiliki Tsaknaki. 2017. Making Preciousness: Interaction Design through Studio Crafts. Ph.D. Dissertation. KTH Royal Institute of Technology.

[43] Vasiliki Tsaknaki, Ylva Fernaeus, and Mischa Schaub. 2014. Leather as a material for crafting interactive and physical artifacts. In Proceedings of the 2014 conference on Designing interactive systems. 5-14.

[44] Anna Vallgårda and Ylva Fernaeus. 2015. Interaction design as a bricolage practice. In Proceedings of the ninth international conference on tangible, embedded, and embodied interaction. 173-180.

[45] Anna Vallgårda and Johan Redström. 2007. Computational composites. In Proceedings of the SIGCHI conference on Human factors in computing systems. 513-522.

[46] Mikael Wiberg, Hiroshi Ishii, Paul Dourish, Anna Vallgårda, Tobie Kerridge, Petra Sundström, Daniela Rosner, and Mark Rolston. 2013. Materiality mattersexperience materials. Interactions 20, 2 (March 2013), 54-57. https://doi.org/10. $1145 / 2427076.2427087$

[47] Nicola Wood. 2008. The new journeyman: The role of an expert learner in eliciting and transmitting skilled knowledge. (2008)

[48] Nicola Wood, Chris Rust, and Grace Horne. 2009. A tacit understanding: The designer's role in capturing and passing on the skilled knowledge of master craftsmen. International fournal of Design 3, 3 (2009). 
[49] Clement Zheng and Michael Nitsche. 2017. Combining Practices in Craft and Design. In Proceedings of the Eleventh International Conference on Tangible, Embedded, and Embodied Interaction (TEI '17). Association for Computing Machinery, New York, NY, USA, 331-340. https://doi.org/10.1145/3024969.3024973
[50] Amit Zoran and Leah Buechley. 2012. Hybrid Reassemblage: An Exploration of Craft, Digital Fabrication and Artifact Uniqueness. Leonardo 46, 1 (Oct. 2012), 4-10. https://doi.org/10.1162/LEON_a_00477 Publisher: MIT Press. 